\title{
Emotional Intelligence and Self-Efficacy Among Physical Education Teachers
}

\section{Alexandre Mouton, Michel Hansenne, Romy Delcour, and Marc Cloes}

University of Liege

\begin{abstract}
Research has documented a positive association between Emotional Intelligence (EI) and well-being, performance and self-efficacy. The purpose of the current study was to examine potential associations between EI and self-efficacy among physical education teachers. The Trait Emotional Intelligence Questionnaire (TEIQue) and the Teacher Sense of Efficacy Scale (TSES) were administered to a sample of 119 physical education teachers. The main results show a positive association between EI and self-efficacy, and more particularly that the sociability factor of EI predicted the TSES total score. Moreover, neither age nor teaching time experience was related to EI or self-efficacy scores. These results both confirm and extend previous findings on the association between EI and self-efficacy. Suggestions are provided for specific EI training for physical education teachers.
\end{abstract}

Keywords: teaching, emotion, TEIQue, TSES

Emotional intelligence (EI) is the ability to recognize and express emotions in yourself and to understand the emotions of others. In other words, the construct of EI refers to the individual differences in the perception, processing, regulation, and utilization of emotional information. When the EI concept was first introduced, the interest remained limited to a small scientific community until the publication of the book Emotional Intelligence by Daniel Goleman (1995).

Research devoted to EI has now split off into two distinct perspectives- the ability model and the trait model. Both perspectives share the idea that cognitive abilities are not the unique predictor of successful adaptation but that emotional competencies have to be taken into consideration. However, these perspectives markedly differ regarding their conceptualization of such emotional competencies and their measurement (Mikolajczak, Luminet, \& Menil, 2006). On the one hand, ability models (Mayer \& Salovey, 1997) conceive EI as an ability encompassing four dimensions: (a) emotions identification; (b) emotions utilization; (c) emotions understanding and (d) emotions regulation. In this ability perspective, EI is assessed via intelligence-like tests. On the other hand, trait models (Petrides \& Furnham, 2001) consider EI as a multifaceted construct encompassing 13-15 (depending on

Mouton, Delcour, and Cloes are with the Department of Sport Sciences, University of Liege, Liège, Belgium. Hansenne is with the same university, in the Department of Cognitive Sciences. 
the model) emotion-related behavioral dispositions thought to affect the ways an individual would cope with demands and pressures. In this trait perspective, EI is evaluated via personality-like questionnaires. While ability tests capture maximal performance, trait tests aim to capture typical performance (Petrides \& Furnham, 2003).

A vast amount of research has documented a positive association between trait EI and well-being related variables (Petrides, Pita, \& Kokkinaki, 2007; Schutte, Malouff, Simunek, Hollander, \& McKenley, 2002). Trait EI is negatively related to psychopathology (Malterer, Glass, \& Newman, 2008). Trait EI is also a significant moderator of responses to stress (Mikolajczak \& Luminet, 2008; Mikolajczak, Roy, Luminet, Fillée, \& de Timary, 2007). On the other hand, some studies have demonstrated a positive link between EI and performance related variables, like job performance and self-efficacy (Chan, 2004; Sy, Tram, \& O'Hara, 2006).

The relationships between EI and job performance were first studied far from the educational context. Indeed, several lines of evidence suggest a positive influence of EI on job performance contributing to its fast-growing use in the business world (Goleman, Boyatzis, \& McKee, 2002). However, studies investigating relationships between EI and performance at the individual level suggest that the current excitement surrounding the potential benefits from EI in the workplace may be premature or even misplaced. Indeed, although EI appears to be related to performance and effective outcomes in some cases (Bachman, Stein, Campbell, \& Sitarenios, 2000; Bar-On, 1997; Dulewicz \& Higgs, 2000; Janovics \& Christiansen, 2001), the results are very limited and often contradictory (Zeidner, Matthews, \& Roberts, 2004). Moreover, the literature is replete with unsubstantiated generalizations, with much of the existing evidence bearing on the role of EI in occupational success based either on anecdotal, impressionistic evidence and/or unpublished or in-house research (Barrett, Miguel, Tan, \& Hurd, 2001). However, few studies have investigated the relationships between EI and performance at the group level (Day \& Caroll, 2004; Feyerherm \& Rice, 2002; Jordan, Ashkanasy, Härtel, \& Hooper, 2002; Rapisarda, 2002). According to Jordan and Troth (2004), EI and, more particularly, the ability to deal with one's own emotions, allowed team members to be more inclined to listen to alternative viewpoints and to look for superior solutions, without feeling threatened by the possibility of being wrong. Turning toward the educational context, teachers' intrapersonal and interpersonal emotional intelligence were found to significantly predict active coping strategy (Chan, 2008). In teachers, emotion-regulation ability (one of the four dimension of EI) may contribute to greater job satisfaction and feelings of personal accomplishment (Brackett, Palomera, Mojsa, Reyes, \& Salovey, 2010).

Finally, some studies have reported positive associations between EI and the concept of self-efficacy, that is "the belief in one's capabilities to organize and execute the courses of action required to produce given attainments" (Bandura, 1997, p.3). At the school level, perceived self-efficacy beliefs have been powerfully related to meaningful outcomes such as teachers' persistence, enthusiasm, commitment and instructional behavior (Tschannen-Moran \& Woolfolk Hoy, 2001). According to Gibson and Dembo (1984), teachers with high self-efficacy are better able to keep students engaged in learning activities whereas teachers with low self-efficacy demonstrated a lack of persistence and used criticism in feedback given to students. In addition, teacher self-efficacy is related to student 
characteristics such as motivation, achievement and efficacy (Tschannen-Moran, Woolfolk Hoy, \& Hoy, 1998).

Chan (2004) reported that secondary teachers' general self-efficacy was positively predicted by positive regulation (a subscale of the Emotional Intelligence Scale (EIS); Schutte et al., 1998), reflecting teachers' optimism or positive expectancies using mood regulation. Moafian and Ghanizadeh (2009) showed that emotional awareness, interpersonal-relationships and problem solving (based on Bar-On, Emotional Quotient; Bar-On, 2000) were the best predictors of self-efficacy among Iranian English Foreign Language (EFL) teachers. Rastegar and Memarpour (2009) confirmed these results with the Schutte's scale. If self-efficacy is significantly predicted by some components of EI, this suggests that differences between teachers may affect this relationship. This means that it could be useful to suggest coping strategies of mood regulation to enhance self-efficacy among teachers.

As noted earlier, some studies have investigated the relationships between EI and self-efficacy with different EI measures and on different samples (e.g., secondary teachers, EFL teachers). Since the Trait Emotional Questionnaire (TEIQue) developed by Petrides (2009) is probably the most interesting measure of EI (Pérez, Petrides, \& Furnham, 2005), the aim of the current study was to extend the association between EI and self-efficacy on a sample of physical education teachers. Teaching physical education involves daily work based on social and physical interactions, for which the teacher must regulate his or her own emotions, but also those of students and of the key stakeholders of education (e.g., parents, colleagues, school principal). As the school life and experiences of the students are highly emotional, especially in physical education, a teacher must be able to emotionally understand the students to offer meaningful and relevant learning content (Debois, Blondel, \& Vettraino, 2007). A teacher's interpretation of student emotion is linked to her thinking and decisions about educational content, curriculum, and pedagogy (McCaughtry, 2004). Therefore, we predict some association between the sociability factor of the TEIQue and self-efficacy among physical education teachers.

\section{Methods}

\section{Participants}

Participants in the current study were 119 elementary $(n=27)$ and secondary $(n=$ 92) physical education teachers from different schools in the French speaking part of Belgium. The convenient sample consisted of 53 females and 66 males-all white Caucasians-with a mean age of 42.1 years $(S D=10.3)$. Their physical education teaching experience ranged between one and 38 years, with a mean of 18.2 years $(S D=10.9)$. The participants were solicited to participate voluntarily in the study.

\section{Emotional Intelligence and Self-Efficacy assessments}

Global Trait Emotional Intelligence was assessed using the French version of the Trait Emotional Intelligence Questionnaire (TEIQue; Petrides, 2009). The TEIQue consists of 153 items arranged on a 7- point Likert scale (from strongly agree to strongly disagree). It provides scores for 15 subscales, four factors (wellbeing, self-control, emotionality, and sociability) and global trait EI including all 
the 15 subscale scores. The well-being factor (e.g., I believe I'm full of personal strengths) comprises three subscales (self-esteem, optimism, and happiness); the self-control factor (e.g., I usually try to resist negative thoughts and think of positive alternatives) comprises three subscales (stress management, impulsiveness, and emotional regulation); the emotionality factor (e.g., I'm usually able to express my emotions when I want to) comprises four subscales (emotion perception, emotion expression, empathy, and relationship skills); and the sociability factor (e.g., I usually find it difficult to change other people's opinions) comprises three subscales (social competence, assertiveness, emotion management). Two additional subscales (adaptability and self-motivation) are included in the total score. The TEIQue shows excellent psychometric properties (see Mikolajczak, Luminet, Leroy, \& Roy, 2007 for the psychometric properties of the French adaptation). In the current study only factors and total score were used and Cronbach's alpha ranged from 0.75 to 0.86 .

The Teacher Sense of Efficacy Scale (TSES) (Tschannen-Moran \& Woolfolk Hoy, 2001) was used for assessing self-efficacy. This 24 items scale includes three factors: efficacy in student engagement (e.g., How much can you do to help your students think critically?), efficacy in instructional strategies (e.g., How well can you respond to difficult questions from your students?), and efficacy in classroom management (e.g., To what extent can you make your expectations clear about student behavior?). Each factor comprises of 8 items arranged on a 9-point Likert scale (from nothing to a great deal). The overall reliability of this instrument is high with a Cronbach alpha of 0.94 .

\section{Statistical Analyses}

All statistical analyses were performed using Statistica (9.1) for Windows (Statsoft France, 2010). Differences on TEIQue dimensions and on total score as well as subscores of the TSES between genders were assessed with multivariate analysis of variance (MANOVA), with TEIQue and TSES scores as dependent variables and group (male vs female) as the independent variable. Spearman correlations and stepwise multiple regression analyses were used to examine the relationship between the TEIQue and the TSES.

\section{Results}

The mean scores and standard deviation for TEIQue and TSES scales and their subscales are presented in Table 1. Multivariate analysis showed that female physical education teachers exhibited significantly higher scores for the emotionality factor of the TEIQue, and lower scores for the self-control and sociability factors of the TEIQue than male physical education teachers.

The correlations among the total score and the four factors of the TEIQue and the total score and the three factors of the TSES are summarized in Table 2. Significant positive correlations were found between the total TEIQue score and the total TSES score $(r=.28)$, as well as with the three factors of the TSES (student engagement, $r=.19, p=.04$; instructional strategies, $r=.31, p<.01$; and classroom management, $r=.22, p=.01)$. In contrast, the TSES total score was positively correlated only with the sociability factor of the TEIQue $(r=.36, p<.01)$. The 
Table 1 Comparisons Between Females and Males for the Trait Emotional Intelligence Questionnaire (TEIQue) Total Score and factors as Well as for the Teacher Sense of Efficacy Scale (TSES) Total Score and Factors.

\begin{tabular}{l|c|c|c|c|c}
\hline & Total & Female & Male & $\mathbf{F ( 8 , 1 1 0 )}$ & $\boldsymbol{p}$ \\
\hline Well-being & $145.46 \pm 15.46$ & $144.67 \pm 18.30$ & $146.09 \pm 12.84$ & 0.24 & 0.62 \\
Self-control & $148.08 \pm 21.32$ & $142.88 \pm 24.40$ & $152.25 \pm 17.58$ & 5.91 & 0.01 \\
Emotionality & $189.39 \pm 24.01$ & $195.41 \pm 25.05$ & $184.56 \pm 22.16$ & 6.27 & 0.01 \\
Sociability & $140.38 \pm 18.86$ & $136.45 \pm 19.73$ & $143.54 \pm 17.66$ & 4.26 & 0.04 \\
TEIQue Total & $718.70 \pm 72.57$ & $712.92 \pm 83.31$ & $723.34 \pm 62.93$ & 0.60 & 0.43 \\
Student & $47.92 \pm 8.09$ & $48.22 \pm 6.66$ & $47.68 \pm 9.13$ & 0.13 & 0.71 \\
engagement & & & & & \\
Instructional & $52.37 \pm 7.17$ & $52.52 \pm 7.34$ & $52.25 \pm 7.08$ & 0.04 & 0.83 \\
strategies & & & & & \\
Classroom & $56.01 \pm 7.39$ & $55.56 \pm 6.36$ & $56.36 \pm 8.16$ & 0.34 & 0.56 \\
management & & & & & \\
TSES Total & $156.31 \pm 19.22$ & $156.32 \pm 16.72$ & $156.30 \pm 21.14$ & 0.01 & 0.99 \\
\hline
\end{tabular}

sociability factor of the TEIQue was positively correlated with the three factors of the TSES (student engagement, $r=.27, p<.01$; instructional strategies, $r=.32$, $p<.01$; and classroom management, $r=.34, p<.01$ ). The self-control factor of the TEIQue was positively correlated with the instructional strategies factor of the TSES $(r=.25, p<.01)$. In addition, neither age nor years of physical education teaching was correlated to the TEIQue and the TSES (all $p>.05$ ).

Table 2 Correlations Between the Trait Emotional Intelligence Questionnaire (TEIQue) Total Score and Factors and the Teacher Sense of Efficacy Scale (TSES) Total Score and Factors.

\begin{tabular}{l|c|c|c|c}
\hline & $\begin{array}{c}\text { Student } \\
\text { engagement }\end{array}$ & $\begin{array}{c}\text { Instructional } \\
\text { strategies }\end{array}$ & $\begin{array}{c}\text { Classroom } \\
\text { management }\end{array}$ & TSES Total \\
\hline Well-being & 0.08 & 0.14 & 0.13 & 0.14 \\
Self-control & $\mathrm{p}=.34$ & $\mathrm{p}=.12$ & $\mathrm{p}=.13$ & $\mathrm{p}=.12$ \\
& 0.01 & 0.25 & 0.08 & 0.12 \\
Emotionality & $\mathrm{p}=.95$ & $\mathrm{p}=.006$ & $\mathrm{p}=.38$ & $\mathrm{p}=.18$ \\
& 0.16 & 0.15 & 0.13 & 0.17 \\
Sociability & $\mathrm{p}=.07$ & $\mathrm{p}=.09$ & $\mathrm{p}=.14$ & $\mathrm{p}=.05$ \\
& 0.27 & 0.32 & 0.34 & 0.36 \\
TEIQue total & $\mathrm{p}=0.002$ & $\mathrm{P}<0.001$ & $\mathrm{P}<0.001$ & $\mathrm{P}<0.001$ \\
& 0.19 & 0.31 & 0.22 & 0.28 \\
& $\mathrm{p}=0.04$ & $\mathrm{p}<0.001$ & $\mathrm{p}=0.01$ & $\mathrm{p}=0.001$ \\
\hline
\end{tabular}


Stepwise regressions showed that the TSES total score was explained only by the sociability factor of the TEIQue $\left(\beta=0.39 ; F=4.7 ; p<.01 ; R^{2}=.14\right)$, and that the TEIQue total score was explained only by the instructional strategies factor of the $\operatorname{TSES}\left(\beta=0.31, F=4.6, p=.003 ; R^{2}=.11\right)$.

\section{Discussion}

The main results of the current study showed a positive correlation between EI and self-efficacy among physical education teachers, and that the sociability factor of EI predicted the TSES total score. Moreover, neither age nor teaching experience were related to EI or self-efficacy scores. In addition, females exhibited higher scores for the emotionality factor of EI, and lower scores for the self-control and sociability factors than males. Even if the associations were rather small (i.e., correlations between 0.19 and 0.36 ), the present results may be relevant to the field.

The present results show that females scored higher for the emotionality factor of the TEIQue and scored lower for the self-control and sociability factors of the TEIQue than males. These findings confirm the empirical support for a gender difference on dimensions relating to control and regulation of one's own emotions. Petrides and Furnham (2000) reported higher scores for females on empathic factor of trait EI, whereas males exhibited higher effectiveness for inhibiting emotional expression. As the empathic and emotional expression factors are two main components of the emotionality subfactor as defined by Petrides and Furnham (2001), one can consider the results of Petrides and Furnham (2000) as highly consistent with the present findings. In accordance with previous studies (Di Fabio \& Palazzeschi, 2008; Furnham, 2000), our results showed that males obtained higher scores in the intrapersonal dimension while females scored higher on the interpersonal dimension. Nevertheless, as mentioned by Sánchez-Nùñez, Fernández-Berrocal, Montañez, and Latorre (2008), findings based on self-reports of EI measures are very disparate concerning gender differences. Moreover, this disparity is not only explained by the kind of assessment tool used, either self-report or performance measures, but also by the variability of the sociodemographic characteristics of the sample. Future research may then put the emphasis on the selection of a sufficiently large and consistent sample. However, a representative sample was not conceivable in this study as global data about the physical education teacher population in the French speaking part of Belgium were not available.

The emotionality dimension of EI is not always related to better adaptation and well-being. Indeed, Quoidbach and Hansenne (2009) have recently reported that emotion appraisal was negatively correlated with the health care quality provided by teams. In other words, emotion appraisal without emotion regulation is negatively associated with job performance. High scores on the emotionality factor could therefore restrain the ability of teachers to focus on the interpersonal part of their job as they encounter difficulties to manage their own emotions. Consequently, teaching self-efficacy is affected and opportunities to learn in the appropriate conditions are diminished for students (Jennings \& Greenberg, 2009). Expressing the right level of emotionality regarding to the teaching situation should therefore be a main objective of physical education teacher programs.

In the current study, neither age nor years of teaching experience were correlated with the TEIQue and the TSES. These results are consistent with previous 
studies showing no association between these variables and both EI and self-efficacy among teachers (Chan, 2004; Penrose, Perry, \& Ball, 2007; Rastegar \& Memarpour, 2009). Therefore, one can suggest that efficacy in teaching is independent of age and teaching experience (i.e., young teachers can instruct students as efficiently as older or more experienced colleagues), but rather associated to individual differences in EI and self-efficacy.

Self-control factor of the TEIQue was positively correlated with the instructional strategies factor of the TSES. Instructional strategies are related to items such as "how well can you implement alternative strategies in your classroom", and "how well can you provide appropriate challenges for very capable students". This means that (at the individual level) teachers with high self-control are more able to challenge the diversity of situations encountered in a classroom. Teachers characterized by higher self-efficacy have been found to improve student behavior, learning, and management in the classroom (Chase, Lirgg, \& Carson, 2001), and one can hypothesize that they exhibit improved abilities to organize and adapt their teaching to the diversity of classroom experiences, especially in the context of physical education. Physical education teachers face multiple social interactions in a more complex context than classroom teachers. Teachers who have been prepared to teach physical education have specialized knowledge (i.e., movement skills, observational skills) that help them make appropriate decisions and understand how to develop and maintain productive learning in a highly fluid and fast-moving environment (Rink \& Hall, 2008). Besides, student physiological and psychological reactions to physical fitness, motor development, competition or body expression are highly personal. Each individual must therefore receive an education related to those personal characteristics. The emotional awareness and emotion regulation of physical education teachers could influence the efficacy of this pedagogical relationship. Students in classes taught by physical education specialists, in comparison with nonspecialists, achieve more, have higher fitness levels and exhibit a more positive attitude toward physical activity (Rahim \& Marriner, 1997; Sallis et al., 1997).

If the teachers are more likely to 'clearly organize' pedagogical content regarding everyone's roles and responsibilities, the latter will become more confident in their teaching, with a transition from concern for the self as disciplinarian in the classroom to concern for interpersonal relationships and creator of a caring environment for the student (Lundeen, 2004). Eventually, this progress will keep disruptive emotions and impulses under control and help teachers to be more confident in their ability to teach and use appropriate instructional strategies in the gym. These findings are consistent with the results reported by Magyar et al. (2007), showing that the ability to regulate one's emotions was the most influential emotional skill in a group of sport camps leaders. A physical education teacher with a high level of self-control, providing instructional strategies adapted to the diversity of the physical education class, could therefore implement an optimal classroom environment for the students. This could lead to positive social, emotional and academic outcomes for the student (Jennings \& Greenberg, 2009).

Further exploration into the sociability factor of the TEIQue showed positive correlation with the TSES total score, defining sociability as the main predictor of self-efficacy. Physical education teachers must develop responsibility, encourage social interactions, provide similar rewards and avoid malicious comparisons 
between the students (González-Cutre, Sicilia, Moreno, \& Fernández-Balboa, 2009). Moreover, effective physical education teachers have good listening and communication skills, which in turn help them to nurture their students' confidence. This major role in creating learning environments that promotes social development is one of the main objectives of physical education teaching. For physical education teachers, the importance of social competencies is emphasized by findings indicating that poor social support from teachers may act as a significant factor leading to reduced students' motivation (Bo, Weidong, Haichun, \& Rukavina, 2010). More generally, participants with low score on sociability are unable to understand others' emotions and are less likely to be good networkers, unsure of what to do or say in social situations (Petrides, 2009). Consequently, physical education teachers with high interpersonal skills will be able to instruct students in a more confident way and, eventually, could implement an effective teaching approach. Developing these social skills within physical education teacher education programs with an emphasis on teacher-students interaction could be very interesting as sociability and teaching efficacy are two closely connected concepts. The Prosocial Classroom model (Jennings \& Greenberg, 2009), which highlights the importance of the teachers' social and emotional competence (SEC) for a supportive teacher-student relationship, an effective classroom management, and a successful social and emotional learning program implementation, could therefore be of interest in the physical education context.

Finally, the current study showed that the total TEIQue score was positively correlated with the TSES total score, as well as with the three factors of the TSES. Teacher self-efficacy (i.e., the teacher's belief about their teaching competences, Tschannen-Moran et al., 1998) is largely recognized in the literature as one of the most important variables related to a wide range of positive teaching and learning outcomes (Gibson \& Dembo, 1984; Woolfolk \& Hoy, 1990). Tschannen-Moran et al. (1998) reported the impact of teacher self-efficacy on several outcomes, such as teachers' classroom behaviors, effort and goal-setting, openness to new ideas and willingness to try new methods, planning and organizational competencies, persistence, resilience, commitment and enthusiasm for teaching, and longevity in their chosen career. In addition, teacher self-efficacy has been shown to influence student achievement, attitude and emotional growth and is related to the health of the organization, atmosphere in the school, classroom based decision-making and student self-efficacy (Penrose et al., 2007). As a study carried out on a comparable sample size $(n=158)$ with teachers of other subject matters (i.e., language, math/ science, social studies) showed that self-efficacy beliefs were significantly predicted by the components of perceived emotional intelligence (Chan, 2004), we might carefully hypothesize that the present results with physical education teachers are consistent with previous findings about teaching profession in general. Nevertheless, our research could be considered as an exploratory study. Due to the moderate sample size, the results presented in this study should be interpreted carefully. A potential bias of the participant recruitment might be acknowledged since the physical education teachers' decision to participate in the study could be correlated with traits that affect the study. Moreover, the use of a self-report questionnaire to assess EI and self-efficacy might have induced a social desirability bias leading participants to over-report their interventions so that they would be viewed more favorably by others. To reduce some of these biases, anonymity was strictly respected at each 
step of the data collection and data analysis. Future research should then extend the relationships between EI and self-efficacy in the field of physical education.

Interventions designed to improve EI have recently flourished, particularly among children, managers and other people with affective difficulties (Matthews, Zeidner, \& Roberts, 2002). Despite the huge expansion of EI development methods and the preliminary evidence for their effectiveness, very few EI programs are based on a solid theoretical model and even fewer have been rigorously tested (Matthews et al., 2002). First, these training programs lack a clear theoretical and methodological rationale and use a miscellany of techniques whose psychological bases are sometimes questionable (Matthews et al., 2002; Matthews, Zeidner, \& Roberts, 2007). Second, they usually target only some EI dimensions (e.g., targeting emotion identification but not emotion management) and add a number of skills that are not considered as parts of EI, such as problem resolution, alcohol or drugs prevention, and reduction of violence (e.g., Topping, Holmes, \& Bremmer, 2000). Third, when evaluations of these programs exist, they are often limited to subjective impression right after the training given by teachers for EI training at school or by the director for EI training at work, without considering the long-term effects (Aber, Brown, \& Henrich, 1999; Goleman, 1995; Matthews et al., 2002). Finally, none of the EI training evaluations to date have included a control group.

As regards to these limitations, an experimental study showed a significant increase in emotion identification and emotion management abilities after a theoretically based EI formation in the training group as compared with the control group (Nelis, Quoidbach, Mikolajczak, \& Hansenne, 2009). Moreover, follow-up measures after 6 months revealed that these changes were persistent. Consistent with the previous findings, the same research group showed in a more recent study (Nelis et al., 2011) that EI can increase after a brief training and, more importantly, leads to a wide array of positive consequences (i.e., physical health, mental health, happiness, life satisfaction, global social functioning, and employability). This experimental assessment implemented in a rigorous scientific approach could therefore be considered as an important contribution to an improved quality of teaching by physical education teachers. Nevertheless, in the context of physical education, preservice and ongoing teacher training are often focused on the development of specific knowledge and skills, even though understanding students' emotions may be as critical to make effective decisions about content, curriculum, and pedagogy (McCaughtry, 2004). For instance, The Emotionally Intelligent Teacher training (Brackett \& Caruso, 2006) could pave the way to a specific physical education EI training. It will be important to explore whether these future interventions can result in improvements in EI and self-efficacy for physical education teachers, and, above all, in positive student outcomes.

\section{Conclusions}

The present results show positive correlations between self-efficacy and EI, and more particularly with the sociability factor. Based on those relationships between teacher self-efficacy and positive teaching and learning outcomes, an EI training with reference to the training sessions suggested by Nelis et al. (2009) could be adapted to the specific context of physical education teaching. However, further studies are needed to provide deeper analysis of this relationship between EI and 
self-efficacy in the specific context of physical education teaching. For instance, even if EI and self-efficacy were assessed by validated scales, tools such as interviews, diaries, audio and video recording of physical education lessons could produce more information to understand the teacher's ability to identify, assess, and control his/her own and students' emotions. Moreover, it could be interesting to perform an external evaluation of EI and teacher self-efficacy. Tools such as the TEIQue $360^{\circ}$ (Petrides, 2009) addressed to peers or students could reinforce the accuracy of the results, limiting the biases of self-report assessment via self-perception questionnaires. Indeed, there are many ways that emotions can be communicated consciously and unconsciously. Although teachers may often attempt to mask their feelings, students could be able to appraise the teacher's emotional skills (Sutton \& Wheatley, 2003), providing a cross validation of the teacher's self-perceptions. Finally, given the current lack of uniformity relating to the methodological approach of those concepts, there is a need for a systematic and consistent assessment to extend our knowledge of physical education teaching.

\section{References}

Aber, J.L., Brown, J.L., \& Henrich, C.C. (1999). Teaching conflict resolution: An effective school-based approach to violence prevention. New York, NY: National Center for Children in Poverty, Colombia University.

Bachman, J., Stein, S., Campbell, K., \& Sitarenios, G. (2000). Emotional intelligence in the collection of debt. International Journal of Selection and Assessment, 8, 176-182. doi:10.1111/1468-2389.00145

Bandura, A. (1997). Self-efficacy: The exercise of control. New York, NY: Freeman.

Bar-On, R. (1997). Bar-On Emotional Quotient Inventory (EQ-i): Technical manual. Toronto, Canada: Multi-Health Systems.

Bar-On, R. (2000). Emotional and social intelligence: Insights from the Emotional Quotient Inventory (EQ-i). In R. Bar-On \& J.D.A. Parker (Eds.), Handbook of emotional intelligence: Theory, development, assessment and application at home, school and in the workplace (pp. 363-388). San Francisco, CA: Jossey-Bass.

Barrett, G.V., Miguel, R.F., Tan, J.A., \& Hurd, J.M. (2001). Emotional intelligence: The Madison Avenue approach to science and professional practice. Unpublished paper.

Bo, S., Weidong, L., Haichun, S., \& Rukavina, P.B. (2010). The influence of inadequate teacher-to- student social support on amotivation of physical education students. Journal of Teaching in Physical Education, 29, 417-433.

Brackett, M.A., \& Caruso, D.R. (2006). The emotionally intelligent teacher. Ann Arbor, MI: Quest Education.

Brackett, M.A., Palomera, R., Mojsa, J., Reyes, M., \& Salovey, P. (2010). Emotion regulation ability, job satisfaction, and burnout among British secondary school teachers. Psychology in the Schools, 47, 406-417.

Chan, D.W. (2004). Perceived emotional intelligence and self-efficacy among Chinese secondary school teachers in Hong Kong. Personality and Individual Differences, 36, 1781-1795. doi:10.1016/j.paid.2003.07.007

Chan, D.W. (2008). Emotional intelligence, self-efficacy, and coping among Chinese prospective and in-service teachers in Hong Kong. Educational Psychology, 28, 397-408. doi:10.1080/01443410701668372

Chase, M.A., Lirgg, C.D., \& Carson, R.L. (2001). Development of the Physical Education Teacher Efficacy Scale: Evaluation of reliability, concurrent and construct validity. Paper presented at the meeting of the American Association of Health, Physical Education, Recreation, and Dance Conference, Cincinnati, $\mathrm{OH}$. 
Day, A.L., \& Caroll, S.A. (2004). Using an ability-based measure of emotional intelligence to predict individual performance, group performance, and group citizenship behaviours. Personality and Individual Differences, 36, 1443-1458. doi:10.1016/ S0191-8869(03)00240-X

Debois, N., Blondel, L., \& Vettraino, J. (2007). Les émotions en EPS: Comprendre et intervenir [Emotions in physical education: Understand and intervene]. Paris, France: Editions Revue EP.S.

Di Fabio, A., \& Palazzeschi, L. (2008). Emotion intelligence and self-efficacy in a sample of Italian high school teachers. Social Behavior and Personality, 36, 315-326. doi:10.2224/ sbp.2008.36.3.315

Dulewicz, V., \& Higgs, M. (2000). Emotional Intelligence: A review and evaluation study. Journal of Managerial Psychology, 15, 341-368. doi:10.1108/02683940010330993

Feyerherm, A.E., \& Rice, C.L. (2002). Emotional intelligence and team performance: The good, the bad and the ugly. The International Journal of Organizational Analysis, 10, 343-362. doi:10.1108/eb028957

Furnham, A. (2000). Thinking about intelligence. The Psychologist, 13, 510-515.

Gibson, S., \& Dembo, M. (1984). Teacher efficacy: A construct validation. Journal of Educational Psychology, 76, 569-582. doi:10.1037/0022-0663.76.4.569

Goleman, D. (1995). Emotional intelligence. New York, NY: Bantam Books.

Goleman, D., Boyatzis, R., \& McKee, A. (2002). Primal leadership: Realizing the power of emotional intelligence. Boston, MA: Harvard Business School Press.

González-Cutre, D., Sicilia, A., Moreno, J.A., \& Fernández-Balboa, J.M. (2009). Dispositional flow in physical education: Relationships with motivational climate, social goals, and perceived competence. Journal of Teaching in Physical Education, 28, 422-440.

Janovics, J., \& Christiansen, N.D. (2001). Emotional intelligence at the workplace. Paper presented at the 16th Annual Conference of the Society of Industrial and Organizational Psychology, San Diego, CA.

Jennings, P.A., \& Greenberg, M.T. (2009). The prosocial classroom: Teacher social and emotional competence in relation to student and classroom outcomes. Review of Educational Research, 79, 491-525. doi:10.3102/0034654308325693

Jordan, P.J., Ashkanasy, N.M., Härtel, C.E.J., \& Hooper, G.S. (2002). Workgroup emotional intelligence: Scale development and relationship to team process effectiveness and goal focus. Human Resource Management Review, 12, 195-214. doi:10.1016/S10534822(02)00046-3

Jordan, P.J., \& Troth, A.C. (2004). Managing emotions during team problem solving: Emotional intelligence and conflict resolution. Human Performance, 17, 195-218. doi:10.1207/s15327043hup1702_4

Lundeen, C.A. (2004). Teacher development: The struggle of beginning teachers in creating moral (caring) classroom environments. Early Child Development and Care, 174, 549-564. doi:10.1080/0300443042000187068

Magyar, M.T., Guivernau, M.R., Gano-Overway, L.A., Newton, M., Kim, M., Watson, D.L., \& Fry, M.D. (2007). The influence of leader efficacy and emotional intelligence on personal caring in physical activity. Journal of Teaching in Physical Education, 26, 310-319.

Malterer, M.B., Glass, S.J., \& Newman, J.P. (2008). Psychopathy and trait emotional intelligence. Personality and Individual Differences, 44, 735-745. doi:10.1016/j. paid.2007.10.007

Matthews, G., Zeidner, M., \& Roberts, R.D. (2002). Emotional intelligence: Science and myth. Cambridge, MA: MIT Press.

Matthews, G., Zeidner, M., \& Roberts, R.D. (Eds.). (2007). The science of emotional intelligence: Knowns and unknowns. New York, NY: Oxford University Press.

Mayer, J.D., \& Salovey, P. (1997). What is emotional intelligence? In P. Salovey \& D. Sluyter (Eds.), Emotional development and emotional intelligence: Educational implications (pp. 3-31). New York, NY: Basic. 
McCaughtry, N. (2004). The emotional dimensions of a teachers' pedagogical content knowledge: Influences on content, curriculum and pedagogy. Journal of Teaching in Physical Education, 23, 30-47.

Mikolajczak, M., \& Luminet, O. (2008). Trait emotional intelligence and the cognitive appraisal of stressful events: An exploratory study. Personality and Individual Differences, 44, 1445-1453. doi:10.1016/j.paid.2007.12.012

Mikolajczak, M., Luminet, O., Leroy, C., \& Roy, E. (2007). Psychometric properties of the trait emotional intelligence questionnaire: Factor structure, reliability, construct, and incremental validity in a French-speaking population. Journal of Personality Assessment, 88, 338-353. doi:10.1080/00223890701333431

Mikolajczak, M., Luminet, O., \& Menil, C. (2006). Predicting resistance to stress: Incremental validity of Trait Emotional Intelligence over Alexithymia and Optimism. Psicothema, $18,79-88$.

Mikolajczak, M., Roy, E., Luminet, O., Fillée, C., \& de Timary, P. (2007). The moderating impact of emotional intelligence on the free cortisol responses to stress. Psychoneuroendocrinology, 32, 1000-1012. doi:10.1016/j.psyneuen.2007.07.009

Moafian, F., \& Ghanizadeh, A. (2009). The relationship between Iranian EFL teachers' emotional intelligence and their self-efficacy in Language Institutes. System, 37, 708-718. doi:10.1016/j.system.2009.09.014

Nelis, D., Quoidbach, J., Hansenne, M., Kotsou, I., Weitens, F., Dupuis, P., \& Mikolajczak, M. (2011). Increasing emotional competence improves psychological and physical well-being, social relationships, and employability. Emotion (Washington, D.C.), 11, 354-366. doi:10.1037/a0021554

Nelis, D., Quoidbach, J., Mikolajczak, M., \& Hansenne, M. (2009). Increasing emotional intelligence: (How) is it possible? Personality and Individual Differences, 47, 36-41. doi:10.1016/j.paid.2009.01.046

Penrose, A., Perry, C., \& Ball, I. (2007). Emotional intelligence and teacher self efficacy: The contribution of teacher status and length of experience. Issues in Educational Research, 17, 107-126.

Pérez, J.C., Petrides, K.V., \& Furnham, A. (2005). Measuring trait emotional intelligence. In R. Schulze \& R.D. Roberts (Eds.), International handbook of emotional intelligence (pp. 181-201). Cambridge, MA: Hogrefe \& Huber.

Petrides, K.V. (2009). Technical manual for the Trait Emotional Intelligence Questionnaire (TEIQue; 1st ed., 1st printing). London, England: London Psychometric Laboratory.

Petrides, K.V., \& Furnham, A. (2000). Gender differences in measured and self-estimated trait emotional intelligence. Sex Roles, 42, 449-461. doi:10.1023/A:1007006523133

Petrides, K.V., \& Furnham, A. (2001). Trait emotional intelligence: Psychometric investigation with reference to established trait taxonomies. European Journal of Personality, 15, 425-448. doi:10.1002/per.416

Petrides, K.V., \& Furnham, A. (2003). Trait emotional intelligence: Behavioural validation in two studies of emotion recognition and reactivity to mood induction. European Journal of Personality, 17, 39-57. doi:10.1002/per.466

Petrides, K.V., Pita, R., \& Kokkinaki, F. (2007). The location of trait emotional intelligence in personality factor space. The British Journal of Psychology, 98, 273-289. doi:10.1348/000712606X120618

Quoidbach, J., \& Hansenne, M. (2009). The impact of trait emotional intelligence on nursing team performance and cohesiveness. Journal of Professional Nursing, 25, 23-29. doi:10.1016/j.profnurs.2007.12.002

Rahim, M., \& Marriner, T. (1997). Students' attitudes toward physical activity: Specialist vs. non-specialist. The Alberta Journal of Educational Research, 43, 161-164.

Rapisarda, B.A. (2002). The impact of emotional intelligence on work team cohesiveness and performance. The International Journal of Organizational Analysis, 10, 363-379. doi:10.1108/eb028958 
Rastegar, M., \& Memarpour, S. (2009). The relationship between emotional intelligence and self-efficacy among Iranian EFL teachers. System, 37, 700-707. doi:10.1016/j. system.2009.09.013

Rink, J., \& Hall, T.J. (2008). Research on effective teaching in elementary school physical education. The Elementary School Journal, 106, 207-218. doi:10.1086/529103

Sallis, J.F., McKenzie, T.L., Alcaraz, J.E., Kolody, B., Faucette, N., \& Howell, M.F. (1997). The effects of a 2-year physical education program (SPARK) on physical activity and fitness in elementary school students: Sports, play and active recreation for kids. American Journal of Public Health, 87, 1328-1334. doi:10.2105/AJPH.87.8.1328

Sánchez-Nùñez, M.T., Fernández-Berrocal, P., Montañez, J., \& Latorre, J.M. (2008). Does emotional intelligence depend on gender? The socialization of emotional competencies in men and women and its implications. Electronic Journal of Research in Educational Psychology, 6, 455-474.

Schutte, N.S., Malouff, J.M., Hall, L.E., Haggerty, D.J., Cooper, J.T., Golden, C.J., \& Dornheim, L. (1998). Development and validation of a measure of emotional intelligence. Personality and Individual Differences, 25, 167-177. doi:10.1016/S01918869(98)00001-4

Schutte, N.S., Malouff, J.M., Simunek, M., Hollander, S., \& McKenley, J. (2002). Characteristic emotional intelligence and emotional well-being. Cognition and Emotion, 16, 769-785. doi:10.1080/02699930143000482

Sutton, R.E., \& Wheatley, K.F. (2003). Teachers' emotions and teaching: A review of the literature and directions for future research. Educational Psychology Review, 15, 327-358. doi:10.1023/A:1026131715856

Sy, T., Tram, S., \& O'Hara, L. (2006). Relation of employee and manager emotional intelligence to job satisfaction and performance. Journal of Vocational Behavior, 68, 461-473. doi:10.1016/j.jvb.2005.10.003

Topping, K., Holmes, E.A., \& Bremmer, W. (2000). The effectiveness of school-based programs for the promotion of social competence. In R. Bar-On \& J.D. Parker (Eds.), The handbook of emotional intelligence: Theory, development, assessment, and application at home, school, and in the workplace (pp. 411-432). San Francisco, CA: Jossey-Bass.

Tschannen-Moran, M., \& Woolfolk Hoy, A. (2001). Teacher efficacy: Capturing an elusive construct. Teaching and Teacher Education, 17, 783-805. doi:10.1016/S0742051X(01)00036-1

Tschannen-Moran, M., Woolfolk Hoy, A., \& Hoy, W.K. (1998). Teacher efficacy: Its meaning and measure. Review of Educational Research, 68, 202-248. doi:10.3102/00346543068002202

Woolfolk, A.E., \& Hoy, W.K. (1990). Prospective teachers' sense of efficacy and beliefs about control. Journal of Educational Psychology, 82, 81-91. doi:10.1037/0022-0663.82.1.81

Zeidner, M., Matthews, G., \& Roberts, R. (2004). Emotional intelligence in the workplace: A critical review. Applied Psychology, 53, 371-399. doi:10.1111/j.14640597.2004.00176.x 